\section{References}

1. Pennington DG, McBride LR, Peigh PS, Miller LW, Swartz MT. Eight years' experience with bridging to cardiac transplantation. $J$ Thorac Cardiovasc Surg. 1994;107:472-81.

2. Peterze B, Lonn U, Jansson K, Rutberg H, Casimir-Ahn H, Nylander E. Long-term follow-up of patients treated with an implantable left ventricular assist device as an extended bridge to heart transplantation. J Heart Lung Transplant. 2002;21:604-7.

3. Bank AJ, Mir SH, Nguyen DQ, Bolman RM 3rd, Shumway SJ, Miller
LW, et al. Effects of left ventricular assist devices on outcomes in patients undergoing heart transplantation. Ann Thorac Surg. 2000;69: 1369-75.

4. Sun BC, Catanese KA, Spanier TB, Flannery MR, Gardocki MT, Marcus LS, et al. 100 long-term implantable left ventricular assist devices: the Columbia Presbyterian interim experience. Ann Thorac Surg. 1999;68:688-94.

5. Massad MG, McCarthy PM, Smedira NG, Cook DJ, Ratliff NB, Goormastic M, et al. Does successful bridging with the implantable left ventricular assist device affect cardiac transplantation outcome? J Thorac Cardiovasc Surg. 1996;112:1275-83.

\title{
Fifteen-month circulatory support for sustained ventricular fibrillation by left ventricular assist device
}

\author{
Motonobu Nishimura, MD, Masanori Ogiwara, MD, Masayuki Ishikawa, MD, Syogo Yatsu, MD, Ayumu Masuoka, MD, \\ Nobuyuki Okamura, MD, Kazuhito Imanaka, MD, Masaaki Kato, MD, Haruhiko Asano, MD, and Shunei Kyo, MD, \\ Saitama, Japan
}

$\mathrm{P}$ atients with end-stage heart failure who receive support from a left ventricular assist system (LVAS) have been shown to tolerate malignant ventricular arrhythmia fairly well. ${ }^{1,2}$ The duration of malignant arrhythmia in the previous reports was at most a little more than 10 days. This report describes a patient who has been in sustained ventricular fibrillation (VF) for more than 1 year and has been supported by an LVAS without showing any symptoms.

\section{Clinical Summary}

A 24-year-old woman, who demonstrated dilated cardiomyopathy, was first referred to us for heart failure and ventricular arrhythmia 5 years ago. At that time, she received the maximum medication and did well. She remained well until the age of 23 years, when she returned with profound heart failure and ventricular tachyarrhythmia resistant to medical therapy. Catecholamine was administered, and workup for cardiac transplantation was started. She experienced VF and was resuscitated using the percutaneous extracorporeal membrane oxygenator system (Emersave, Terumo, Tokyo, Japan). She was immediately brought to the operating room, where

From the Department of Cardiovascular Surgery, Saitama Medical School, Iruma-gun, Saitama, Japan.

Received for publication Feb 13, 2003; accepted for publication March 24, 2003.

Address for reprints: Motonobu Nishimura, MD, Department of Cardiovascular Surgery, Saitama Medical School, 38 Moro-hongo, Moroyama, Iruma-gun, Saitama 350-0495, Japan (E-mail: nishimur@ saitama-med. ac.jp).

J Thorac Cardiovasc Surg 2003;126:1190-2

Copyright $\odot 2003$ by The American Association for Thoracic Surgery $0022-5223 / 2003 \$ 30.00+0$

doi:10.1016/S0022-5223(03)00726-8 she underwent emergency placement of the Toyobo-NCVC LVAS (Toyobo, Osaka, Japan) with left ventricular drainage. Her postoperative course was essentially uneventful, but her ventricular arrhythmia continued despite aggressive antiarrhythmia medication. Three months after placement of the LVAS, she experienced VF again, which was resistant to external cardioversion (Figures $1 \mathrm{~A}$ and 1B). Although her heart had been fibrillated, her LVAS flow was almost unchanged (3-4 L/min), and she showed no symptoms. Despite all the attempts to restore her original rhythm, she remained in VF. After several days, we stopped the attempts because she had been well with no symptoms, and further attempts may have caused embolism as the result of intracardiac thrombus. Since then, her heart has been in sustained VF for 15 months, but she has been ambulated, like other patients supported by an LVAS, while awaiting heart transplantation (Figure 2). Although her right ventricle is not working, she has not demonstrated peripheral edema, pleural effusion, or ascites. Her pulmonary vascular resistance before LVAS placement was 2.44 Wood units. Her central venous pressure 3 months after demonstrating VF was approximately $10 \mathrm{~mm} \mathrm{Hg}$. Cardiac catheterization was not performed after sustained VF because of possible thrombus in her fibrillated heart.

\section{Discussion}

Sustained VF is not a lethal arrhythmia for patients supported by an LVAS. In a report by $\mathrm{Oz}$ and associates, ${ }^{1}$ an LVAS was successful in supporting 9 patients who continued to experience malignant ventricular arrhythmia during device support. The arrhythmias lasted from 10 minutes to 12 days. The patients reported weakness, but none reported syncope. Fasseas and coworkers ${ }^{3}$ reported the successful use of an LVAS for the management of refractory ventricular arrhythmia. Nonetheless, early electrical cardioversion is indicated in patients demonstrating sustained VF with LVAS support because usually there is more than a $1 \mathrm{~L} / \mathrm{min}$ decrease in device flow at the onset of $\mathrm{VF}^{1}$ 


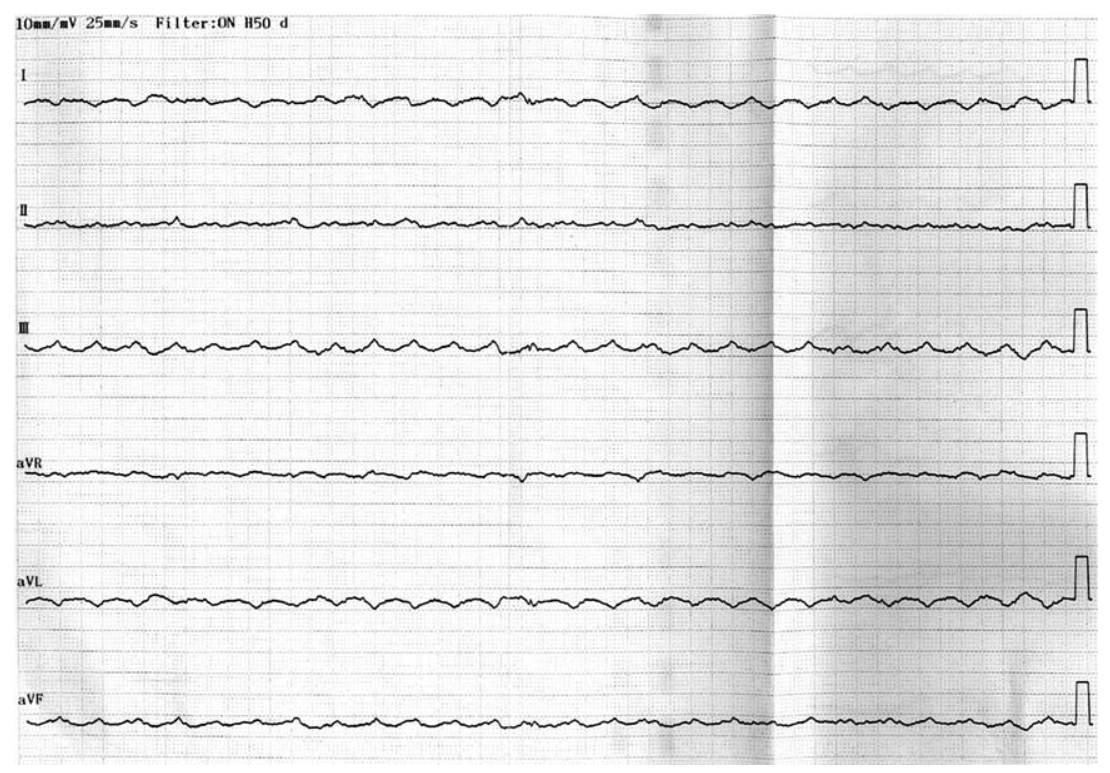

Figure 1A. Electrocardiogram of limb leads shows sustained VF 1 year after the onset of VF.

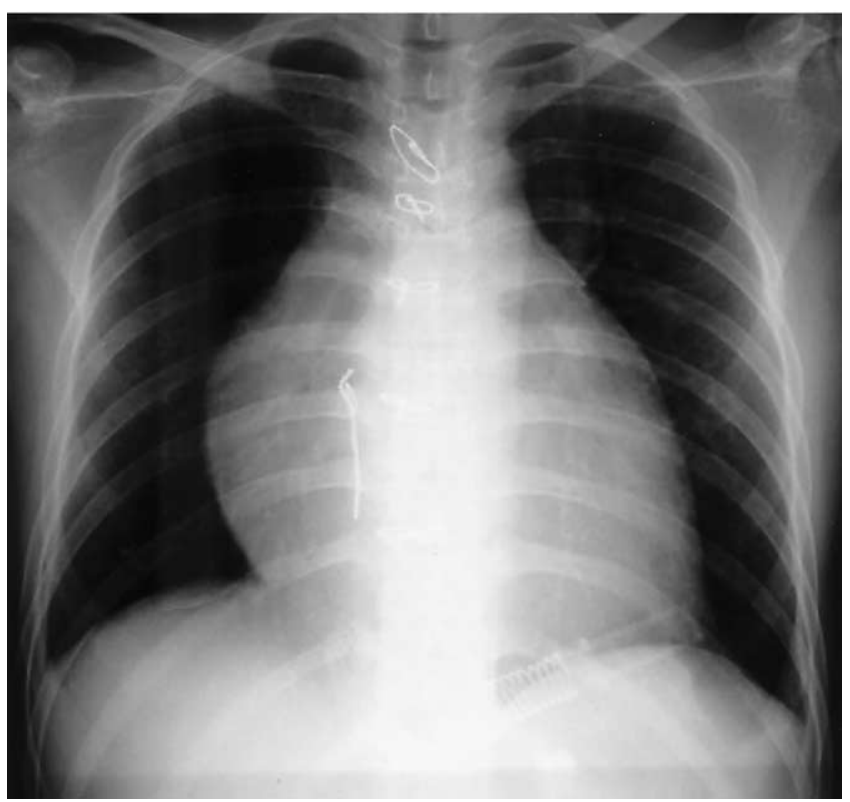

Figure 1B. Chest $x$-ray film 1 year after the onset of VF shows no pulmonary congestion but marked dilation of the right side of the heart.

This is a rare case of a patient who has demonstrated sustained VF for more than 1 year and has been successfully supported by an LVAS. She is ambulatory without showing any symptoms, which is one of the reasons that we stopped attempting cardioversion. Otherwise, placement of a right ventricular assist device would be indicated in this setting as reported by Farrar and colleagues. ${ }^{4}$

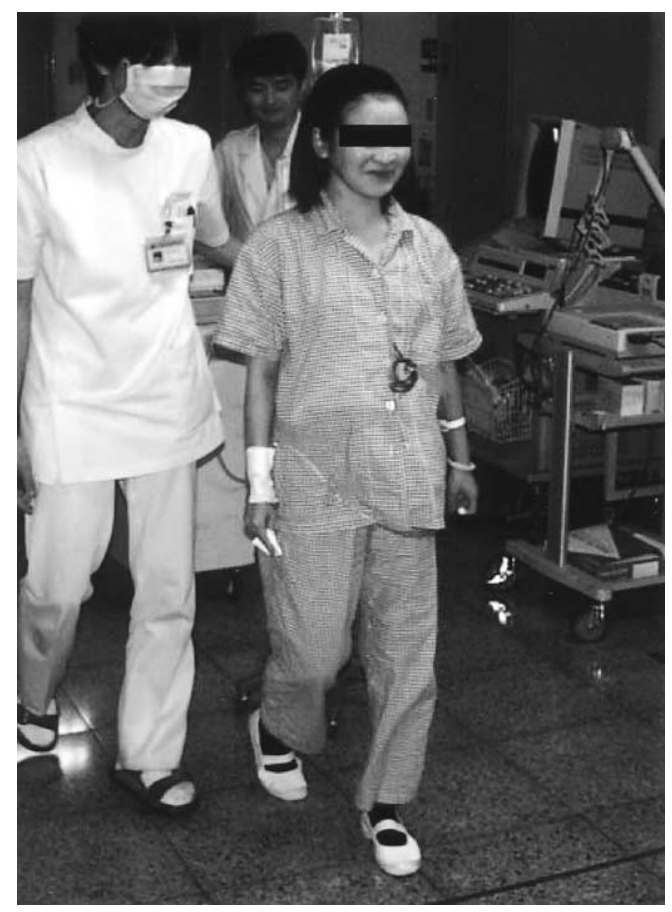

Figure 2. The patient with paracorporeal LVAS is walking in the hallway while her heart is in VF.

There are 2 reasons why she remains in good shape in sustained VF while supported by an LVAS: (1) She has normal pulmonary vascular resistance (2.44 Wood units), which allows her a kind of Fontan circulation with an LVAS. (2) Her body size (body surface area of $1.42 \mathrm{~m}^{2}$ ) is small enough to maintain whole circulation with 1 Toyobo-NCVC LVAS, a pneumatically driven paracorpo- 
real ventricular assist device developed in Japan. However, although she is able to walk around the hallway, her exercise capacity is very limited. Her latest data of peak oxygen consumption during exercise was $6.9 \mathrm{~mL} \cdot \mathrm{min}^{-1} \cdot \mathrm{kg}^{-1}$. Additional placement of a right ventricular assist device may improve her exercise capacity, but the risk of device-related complication would increase with biventricular assist. In Japan, the mean waiting period for a status- 1 heart transplant candidate is more than 1 year. To minimize possible complication, univentricular assist is better for prolonged support lasting more than 1 year.

Experimentally, Takano and coworkers ${ }^{5}$ have shown the possibility of prolonged circulatory maintenance with an LVAS by studying goats in VF. To our knowledge, this is the first clinical case demonstrating that long-term circulatory support of a non-heart-beating patient is possible with left ventricular support only, when pulmonary vascular resistance is in the normal range.

\section{References}

1. Oz MC, Rose EA, Slater J, Kuiper JJ, Catanese KA, Levin HR. Malignant ventricular arrhythmias are well tolerated in patients receiving long-term left ventricular assist devices. J Am Coll Cardiol. 1994;24:1688-91.

2. Fasseas P, Kutalek SP, Kantharia BK. Prolonged sustained ventricular fibrillation without loss of consciousness in patients supported by a left ventricular assist device. Cardiology. 2002;97:210-13.

3. Fasseas P, Kutalek SP, Samuels FL, Holmes EC, Samuels LE. Ventricular assist device support for management of sustained ventricular arrhythmias. Tex Heart Inst J. 2002;29:33-6.

4. Farrar DJ, Hill JD, Gray LA Jr, Galbraith TA, Chow E, Hershon JJ. Successful biventricular circulatory support as a bridge to cardiac transplantation during prolonged ventricular fibrillation and asystole. Circulation. 1989;80(5 Pt 2):III147-51.

5. Takano H, Taenaka Y, Nakatani T, Noda H, Kinoshita M, Fukuda S, et al. Experimental studies of prolonged circulatory maintenance with a left ventricular assistance in cardiac arrested goats. Nippon Kyobu Gakkai Zasshi. 1989;37:411-22.

\section{Combination of the HEARTSTRING proximal seal system with a blower mister: A possible source of gas emboli}

Georg Nollert, MD, Martin Oberhoffer, MD, Bruno Reichart, MD, and Calin Vicol, MD, Munich, Germany

$\mathrm{U}$ sing a side clamp for the performance of proximal anastomoses in coronary artery bypass surgery may injure the ascending aorta and cause intimal tears, with subsequent dissection or debridement of atherosclerotic material and stroke. Several devices were developed to perform proximal bypass anastomoses without the necessity of side clamping, the latest being the HEARTSTRING proximal seal system (Guidant Corp, Santa Clara, Calif). The system comprises the proximal seal, a delivery device, and an aortic punch. The proximal seal is delivered into the aorta via a punch hole site and provides a sealed region to facilitate the proximal anastomosis. ${ }^{1}$ The proximal seal covers the punch hole from inside the aorta, because the blood pressure pushes and a tension spring mechanism pulls the seal against the aortic wall.

\footnotetext{
From the Department of Cardiac Surgery, University of Munich, Munich, Germany.

Received for publication March 11, 2003; accepted for publication April 8, 2003.

Address for reprints: Dr Georg Nollert, Department of Cardiac Surgery, Klinikum Grosshadern, Marchioninistr 15, 81366, Munich, Germany (Email: gnollert@hch.med.uni-muenchen.de).

J Thorac Cardiovasc Surg 2003;126:1192-4

Copyright $\odot 2003$ by The American Association for Thoracic Surgery $0022-5223 / 2003 \$ 30.00+0$

doi:10.1016/S0022-5223(03)00800-6
}

\section{Patient}

The first use of the HEARTSTRING device in our clinic was scheduled in an 83-yearold woman who presented with unstable angina. Three bypasses were implanted including the left internal thoracic artery connected to the left anterior descending and 2 saphenous vein grafts for the first diagonal branch and the distal right coronary artery. The proximal anastomoses were performed with the aid of the HEARTSTRING device after removal of the crossclamp without using a side clamp. Because of bleeding during the performance of the proximal anastomoses, the operative field was cleared with a blower mister (Medtronic Inc, Minneapolis, Minn) as recommended by the manufacturer. ${ }^{1}$ Mean arterial pressure was above $70 \mathrm{~mm} \mathrm{Hg}$. Postoperatively the patient was hemodynamically stable without inotropic support. As the patient did not wake up a cerebral computed tomography (CT) scan was performed immediately followed by a second $\mathrm{CT}$ of the brain, thorax, and abdomen 11 hours later. It revealed a new hypodense right frontal area $(2 \times 2 \mathrm{~cm}$ large $)$ in the region of the anterior cerebral artery (see Figure 1) and multiple spleen infarctions.

\section{Animal Experiment}

A German land race pig ( $35 \mathrm{~kg}$ ) was anesthetized, intubated, and ventilated. For arterial blood pressure monitoring as well as blood gas sampling, the right carotid artery was cannulated. The chest 